\title{
Multisegmental cervical ossification of the posterior longitudinal ligament: Anterior vs posterior approach
}

\author{
Subodh K. Jain, Pravin S. Salunke, K. H. Vyas, Sanjay S. Behari, Deepu Banerji, Vijendra K. Jain \\ Department of Neurosurgery, Sanjay Gandhi Post Graduate Institute Of Medical Sciences, Raebareli Road, Lucknow, Uttar Pradesh, India
}

\begin{abstract}
Aims: To determine the surgical approach in patients with multisegmental (four or more segments) OPLL of the cervical spine. Methods and Materials: Data of 27 patients who had undergone either an anterior (corpectomy with excision of OPLL and interbody fusion=14 patients) or posterior approach (laminectomy=12, laminoplasty=1 patient) for the multisegmental cervical OPLL was analyzed retrospectively. The patients in each group were statistically similar in respect to preoperative factors such as age, duration of symptoms, preoperative modified Japanese orthopedic association score, OPLL thickness, effective canal diameter, and antero-posterior cord compression ratio. The clinical outcome was assessed by the Harsh grading system and recovery rate was assessed by Hirabayashi method. Results: There was no statistical difference in the outcome, and recovery rate. Nine patients developed complications after anterior approach in contrast to one after posterior approach. Conclusions: In patients with multisegmental cervical OPLL, there was no significant difference in the short-term recovery rate and outcome between two groups. The immediate postoperative complications were less in patients who had undergone posterior approach. From our analysis, it appears that the posterior approach is probably the preferred method of treatment in a multisegmental OPLL in absence of preoperative kyphosis.
\end{abstract}

Key words: cervical spine; laminoplasty; ossification of the posterior longitudinal ligament; spinal instrumentation.

Several previous studies have analyzed the results of anterior or posterior surgical approach in patients with ossification of the posterior longitudinal ligament (OPLL) of the cervical spine. ${ }^{[1-5]}$ In this study, we compare the results of anterior and posterior surgical approach in an identical cohort of patients having multisegmental cervical OPLL.

\section{Materials and methods}

During the period between January 1996 and January 2004, 55 patients with cervical OPLL were operated. These patients were analyzed retrospectively. Twenty-seven patients had multisegmental OPLL (four or more segments). Out of 27 patients, 14 underwent anterior approach (corpectomy with excision of OPLL and interbody fusion using iliac crest bone graft). Three-level corpectomy was done in 13 patients and four-level corpectomy was done in one patient. Metal instrumentation was not done in any patient. The remaining 13 patients underwent posterior approach. C2-7 laminectomy was done in 12 patients and open door laminoplasty (C2-7) was done in one patient. In seven cases of laminectomy and one of laminoplasty pneumatic drill was used. For the remaining five patients laminectomy was done using roungers and micropunches. There were four patients who had cervical kyphosis or straight spine and all of them underwent an anterior approach. For the remaining 23 patients the criteria for any particular approach were not outlined.

The severity of myelopathy was assessed using Harsh grading scale in all the patients [Table 1]. ${ }^{[6]}$ Considering the added advantage of modified Japanese orthopedic association score (mJOAS) over Harsh grade in assessing the motor and sensory deficits along with disability and sphincteric dysfunction, all patients were also assessed using mJOAS. ${ }^{[7,8]}$

The curvature of spine, maximum OPLL thickness and the effective canal diameters were measured on plain X-ray. Type of OPLL was classified according to Hirabayashi classification. ${ }^{[9]}$ (Segmental: located behind the vertebral body; continuous: extends from body to body; mixed: both segmental and continuous components; others: confined to dise space.) Antero-posterior cord compression ratio (APCR) was measured as the percentage ratio of smallest sagittal to maximum transverse diameter of the cord at the level of compression on T1 weighted, axial MRI [Figure 1]. ${ }^{[10]}$ 
Post operative mJOAS - Preoperative mJOAS Total score (17) - Preoperative mJOAS X 100.

Mean follow-up period was 13 months, which was similar for both the groups, with maximum follow up of 36 months. At follow up, the neurological improvement or deterioration was assessed by two parameters, i.e., outcome and recovery rate. The outcome could be good (Harsh grades I, II), fair (Harsh IIIa, IIIb), or poor (Harsh IIIc, IV). The recovery rate was used to quantify the extent of neurological improvement or deterioration. The 'Recovery rate' was calculated in percentage by the method described by Hirabayashi, ${ }^{[11]}$ i.e.,

\section{Statistical analysis}

The statistical method of analysis was done using MannWhitney test. Statistical significance was reached if the $P$ value was $£ 0.05$.

\section{Results}

Twenty-four patients were males and three were females. Age ranged from 30 to 74 years and the mean age was 53.74 $( \pm 9.8)$ years. The mean duration of symptoms at presentation was 18.2 (range 2-60) months. Spasticity was present in $26(96 \%)$ patients, and motor weakness in $19(70.4 \%)$. Ten $(37 \%)$ patients had sensory dysfunction and 10 patients $(37 \%)$ had sphincteric dysfunction. Six $(22 \%)$ patients had radicular pain or neck pain. Three patients had history of trauma leading to deterioration.

There was no difference in the curvature of spine, level and type of OPLL in the two groups [Table 2]. Four patients had a fixed kyphotic deformity or loss of normal lordosis (straight spine). The factors like age of the patient, duration of symptoms, preoperative mJOAS, OPLL thickness, effective canal diameter, and APCR were similar in the two groups and there was no significant statistical difference ( $P$ value $>0.05$ for all factors compared) [Table 3].

The surgical outcome of patients with multisegmental cer-

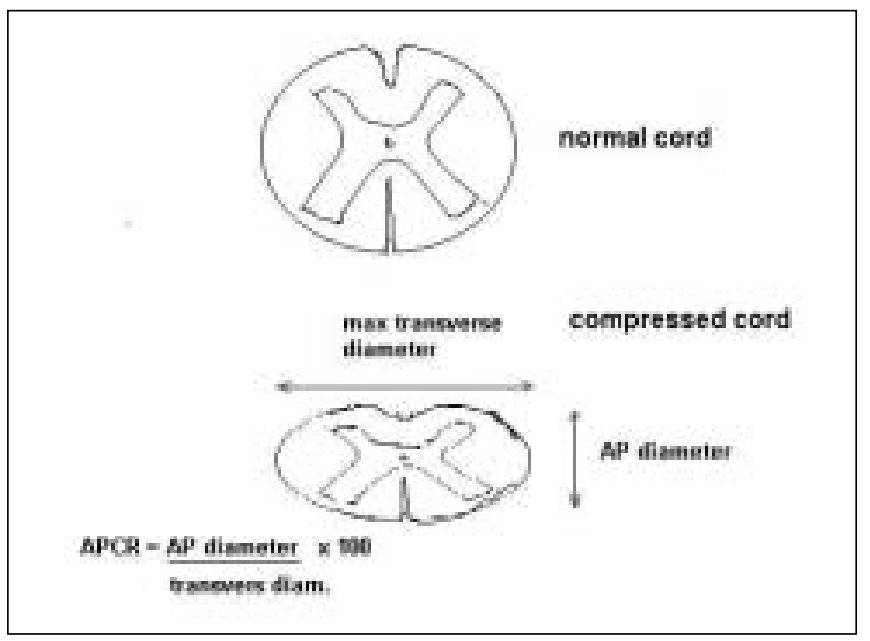

Figure 1: Antero-posterior cord compression ratio vical OPLL who had undergone anterior and posterior approach is shown in [Table 4]. Good outcome was observed in 71 and $61 \%$ of the patients who had undergone anterior and posterior approach, respectively. The mean recovery rate was $63.27( \pm 20.21)$ and $58.85( \pm 15.38)$ in patients with anterior and posterior approach, respectively. There was no statistical difference (using Mann-Whitney test) in number of patients with good outcome $(P=0.09)$, and recovery rate $(P=1.3)$ between the two groups.

The postoperative complications in patients who had undergone a posterior approach were less frequent as compared to those with anterior approach. In the posterior surgery

\begin{tabular}{lc}
\hline & Table 1: Harsh myelopathy grading \\
\hline Grade & Severity of myelopathy \\
Grade 0 & No evidence of myelopathy \\
Grade I & Able to run, but abnormal reflexes \\
Grade II & Difficulty in running or climbing stairs \\
Grade III & \\
IIIa & Difficulty in walking but independent \\
IIIb & Cane or crutch \\
IIIc & Walker or assistant \\
Grade IV & Difficulty in standing/bed ridden \\
\hline
\end{tabular}

Table 2: Comparison of curvature of the spine, level, and type of ossification of posterior longitudinal ligament (OPLL) in two groups

\section{Anterior approach Posterior approach} $(n=14)$ $(n=13)$

Curvature of the spine

Lordosis

10

Kyphosis

Level of OPLL

$\mathrm{C} 2-\mathrm{C} 5$

C3-C6

$\mathrm{C} 4-\mathrm{C} 7$

$\mathrm{C} 2-\mathrm{C} 6$

$\mathrm{C} 3-\mathrm{C} 7$

$\mathrm{C} 2-\mathrm{C} 7$

$\begin{array}{ll}3 & - \\ 5 & 6 \\ - & 1 \\ 4 & 1 \\ - & 1 \\ 2 & 4\end{array}$

Type of OPLL

Continous $\quad 10 \quad 11$

$\begin{array}{lll}\text { Mixed } & 4 & 2\end{array}$

Table 3: Comparison of the preoperative factors between the two groups*

\begin{tabular}{|c|c|c|}
\hline & $\begin{array}{l}\text { Anterior approach } \\
(n=14)\end{array}$ & $\begin{array}{l}\text { Posterior approach } \\
(n=13)\end{array}$ \\
\hline Preoperative factors & Mean $\pm S D$ & Mean $\pm S D$ \\
\hline Age (years) & $51.5 \pm 8.4$ & $56.1 \pm 10.8$ \\
\hline $\begin{array}{l}\text { Duration of symptoms } \\
\text { (months) }\end{array}$ & $20 \pm 19$ & $16.3 \pm 10.9$ \\
\hline Preoperative mJOAS & $7.5 \pm 2.5$ & $9.1 \pm 2.2$ \\
\hline OPLL thickness & $6.2 \pm 1.5$ & $5.8 \pm 0.9$ \\
\hline Effective canal diameter & $4.8 \pm 2.4$ & $5.0 \pm 2.5$ \\
\hline APCR & $14.5 \pm 7.6$ & $18.0 \pm 4.6$ \\
\hline
\end{tabular}

SD, Standard deviation; mJOAS, modified Japanese orthopedic association score; OPLL, ossification of posterior longitudinal ligament; APCR, antero-posterior cord compression ratio.

${ }^{*}$ No significant difference found using Mann-Whitney test between the two groups. 
group, one patient worsened in power in all limbs following laminectomy but progressively improved to the preoperative status. The cause for this deterioration was not clear but was probably due to nonusage of drill. Nine patients had complications following anterior approach. Two of them had deterioration in power in all limbs, and were given methylprednisolone following which one improved to the preoperative grade and the other patient did not show any improvement. The same patient required postoperative ventilatory support for 3 days after which he could be weaned off. The cause of deterioration was probably cord handling during OPLL excision. Three patients had CSF leak from the anterior wound and required lumbar drainage. One patient had graft extrusion for which he was re-explored. The graft, which was slightly longer was refashioned and repositioned. One patient each had respiratory distress and dysphagia following surgery.

There was no significant difference in the outcome, and recovery rate between the two groups. There was no mortality in either group.

\section{Discussion}

The advantage of anterior surgical approach in cases with multisegmental OPLL includes effective decompression of the OPLL and the possibility of prevention of progression of the OPLL. ${ }^{[5]}$ However, the anterior approach is relatively more difficult and carries potential risks of graft extrusion, CSF leak, excessive venous bleeding, and dysphagia. ${ }^{[12]}$ The advantages of posterior decompression is that the operation is relatively straightforward. ${ }^{[13]}$ However, the possibility of progression of OPLL, postlaminectomy membrane formation, kyphotic deformity, and instability of the cervical spine remains. ${ }^{[3,14,15]}$ For multilevel cervical spodylotic myelopathy, laminoplasty may be the preferred method of treatment in absence of preoperative kyphosis. ${ }^{[16]}$

In our study, the results of anterior and posterior approach in patients with multisegmental cervical OPLL were compared. There was no significant difference in the outcome, and shortterm recovery rate between the two groups. Considering the higher rate of complications with the anterior surgery group, it appears that the posterior approach could be preferable for patients with multisegmental cervical OPLL with cervical lordosis.

Hirabayashi et al., analyzed the results of laminectomy in patients with OPLL and reported that the most common cause of deterioration was the progression of the OPLL. ${ }^{[11]}$ How- ever the follow-up period in our study is relatively short and the progression of OPLL and kyphotic deformity could not be evaluated. As laminectomy carries certain known disadvantages like kyphotic deformity, progression of OPLL, postlaminectomy membrane formation and instability of the cervical spine, it has now been commonly replaced by laminoplasty for multisegmental cervical OPLL. ${ }^{[5,15]}$ The rate of progression of the OPLL and kyphotic deformity after laminoplasty is believed to be lower than that after laminectomy. $^{[5,13,15]}$

\section{References}

1. Cheng WC, Chang CN, Lui TN, Lee ST, Wong CW, Lin TK. Surgical treatment for ossification of the posterior longitudinal ligament of the cervical spine. Surg Neurol 1994;41:90-7.

2. Epstein N. The surgical management of ossification of the posterior longitudinal ligament in 51 patients. J Spinal Disord 1993;6:432-54

3. Epstein N. Posterior approaches in the management of cervical spondylosis and ossification of the posterior longitudinal ligament. Surg Neurol 2002;58:194-207

4. Banerji D, Acharya R, Behari S, Chhabra DK, Jain VK. Corpectomy for multilevel cervical spondylosis and ossification of the posterior longitudinal ligament. Neurosurg Rev1997;20:25-31.

5. Yonenobu K, Yamamoto T, Ono K. Surgical management of ossification of the posterior longitudinal ligament: Anterior versus posterior approach, part I. In: The Cervical Spine Research Society Editorial Committee, ed. The Cervical Spine. 3rd Ed. Lippincott-Raven: Philadelphia; 1998. p. 865-76.

6. Harsh GR $4^{\text {th }}$, Sypert GW, Weinstein PR, Ross DA, Wilson CB. Cervical spine stenosis secondary to ossification of the posterior longitudinal ligament. J Neurosurg 1987;67:349-57

7. Benzel EC, Lancon J, Kesterson L, Hadden T. Cervical laminectomy and dentate ligament section for cervical spondylotic myelopathy. J Spinal Disord $1991 ; 4: 286-95$.

8. Hukuda S, Mochizuki T, Ogata M, Shichikawa K, Shimomura Y. Operations for cervical spondylotic myelopathy: A comparison of the results of anterior and posterior procedures. J Bone Joint Surg Br 1985;67:609-15.

9. Hirabayashi K, Watanabe K, Wakano K, Suzuki N, Satomi K, Ishii Y. Expansive open-door laminoplasty for cervical spinal stenotic myelopathy. Spine $1983 ; 8: 693-9$

10. Koyanagi I, Iwasaki Y, Hida K, Imamura H, Abe H. Magnetic resonance imaging findings in ossification of the posterior longitudinal ligament of the cervical spine. J Neurosurg 1998;88:247-54.

11. Hirabayashi K, Miyakawa J, Satomi K, Maruyama T, Wakano K. Operative results and postoperative progression of ossification of the longitudinal ligament. Spine 1981;6:354-64.

12. Macdonald RL, Fehlings MG, Tator CH, Lozano A, Fleming JR, Gentili F, et al. Multilevel anterior cervical corpectopmy and fibular allograft fusion for cervical myelopathy. J Neurosurg 1997;86:990-7.

13. Tomita K, Nomura S, Umeda S, Baba H. Cervical laminoplasty to enlarge the spinal canal in multilevel ossification of the posterior longitudinal ligament with myelopathy. Arch Orthop Trauma Surg 1988;107:148-53.

14. Hansen-Schwartz J, Kruse-Larsen C, Nielsen C.J. Follow-up after cervical laminectomy, with special refernce to instability and deformity. $\mathrm{Br}$ J Neurosurg $2003 ; 17: 301-5$

15. Iwasaki M, Kawaguchi Y, Kimura T, Yonenobu K. Long term results of expansive laminoplasty for ossification of the posterior longitudinal ligament of the cervical spine: more than 10 years follow up. J Neurosurg 2002;96:180-9.

16. Edwards CC $2^{\text {nd }}$, Heller JG, Murakami H. Corpectomy versus laminoplasty for multilevel cervical myelopathy. Spine 2002;27:1168-75.

Accepted on 05-06-2005 


\section{Invited Comments}

The authors addressed an interesting and challenging entity: multisegmental OPLL. The study has a retrospective character. The numbers seem to be small, but were quite impressive when related to the incidence and prevalence of the disease. Several lessons can be learned from the study.

Although the pathology is located anterior to the spinal cord, OPLL is often closely adhered to the dura. Dissection is difficult, and the risk of CSF leakage and neurological deterioration is high. This is also shown in the present series. Furthermore, grafting with iliac crest over more than two levels has a significant risk of graft extrusion, subsidence, and especially pseudoarthrosis. These risks are even higher when instrumentation is not used. Although the authors did not mention whether they braced (halo?) the patients postoperatively, the complication rate related to the grafting is within the normal range for instrumented spondylodesis. Because the outcome seemed to be equal, complications directed the choice of the final treatment. In this case, laminectomy or laminoplasty clearly has less complications, and is therefore the treatment of choice. Although not investigated, one could argue whether in case of a straight or kyphotic cervical spine, a posterior decompression should be followed by an arthrodesis to prevent progression of the kyphotic deformity. Sometimes it is possible to reduce a straight or kyphotic spine in a lordotic spine. Personally, I prefer preoperative flexion and extension $\mathrm{X}$-rays. If during extension a lordotic shape is seen, a posterior decompression is performed. The head of the patient is fixed in the Mayfield clamp, and under fluoroscopic guidance the neck is extended until a slightly lordotic shape is seen. Then the surgery is performed and an instrumented arthrodesis performed. This is extended to Th1 or Th2.

Ronald H. M. A. Bartels

Department of Neurosurgery, Radboud University, Nijmegen Medical Centre. R. Postlaan 4, 6500 HB Nijmegen, The Netherlands E-mail: r.bartels@nch.umcn.nl 